\title{
Agricultural Updates Using Multitenant Cloud Infrastructure In Distributed Environment
}

\author{
S.Divya $^{1}$, M.Mathivani ${ }^{2}$,Priyanga Sivaprasad ${ }^{3}$, S.Uma $^{4}$ \\ Department of Information Technology, Panimalar Engineering College, Chennai ${ }^{1-4}$ \\ Guide, Department of Information Technology, Panimalar Engineering College, Chennai
}

\begin{abstract}
India is an agriculture based developing country. Cloud computing plays a major role in the field of agriculture. It is an emerging style of computing in which applications, data and resources are provided as service to the user in the web. Some practical challenges that are faced while communicating among the farmers are Poor knowledge about weather forecast, deficient production information, information about sales and distribution. Creating a network that goes beyond the one-to-one, farmer to farmer, farmer to expert interactions. A cloud based framework is designed to provide the updates on the website and application that would be helpful to the user to get required information anytime and anywhere through a common gateway.
\end{abstract}

Keywords: Cloud computing, DE, Expert interactions

\section{INTRODUCTION}

This Agriculture is the essential control of the bigger piece and may have diverse particular substance can be of Indian populace. 65-70\% of Indian populace is being heterogeneous in their structure and configuration .

relies on upon agriculture for their living. The testing Subsequently it is required to build up a framework from errand for farmers is data administration for the most part where the required data is accessible to the farmer as far as the measure of information and the straightforwardly. New open doors are formed by unpredictability of forms in exactness cultivating. The advanced mobile phone innovation for agriculturists. information with respect to cultivating are accessible from Agriculturists are skilled with a minimal effort advanced many sources like printed media, sound and visual helps, mobile phone and the specific programming to pick up daily paper, TV, web, versatile and so on however the offices which couldn't accessible on their hands some time organizations and structures of information are divergent. recently. In the times of money related emergency, So it's hard for farmer to get the data and to comprehend cultivating is turning out to be increasingly vivacious the different data which are scatter from different sources. what's more, a great deal more imperative to be finished At some point numerous manual strides are required while proficiently amid the day and age. A few portable preparing information for changing information starting applications have been created for procurement of with one organization then onto the next. The movement information in the field, domesticated animals in the agriculture creation straight expands the Indian administration, AgroMobile, Krishiville and so on. This Economy and bad habit- versa is likewise valid. Versatile paper manages the examination of accessible android applications in the field of agribusiness can be the best based applications which are helpful for agriculturists.

choice to increment countries' agriculture creation. The innovations in innovation in agribusiness area are definitely not getting

to the farmers; on account of either the greater part of them are ignorant people or because of ignorance of the area from where they can have data. Henceforth, most extreme of the farmers is being bombed in procurement of the conceivable creation rate Today agriculturists are getting assorted truths or data about faming like seeds, harvest choice, edit forms drawback of this system is problem in network. Due to the problems the messages are not delivered properly and the information in the message differs from the information which is requested by the farmers.climate, compost, pesticides and so on from different assets which are dispersed on many diverse areas as indicated by its starting point, its processors, makers or sellers. The information having distinctive arrangement

\section{RELATED WORK}

\subsection{AGRICULTURE UPDATES VIA SMS -A CLOUD COMPUTING APPROACH}

Praveen B. and Viswesh M.

They described the use of simple messaging system in agricultural sectors. Here the farmer requests the agricultural officer about the details they require and they get the information related to their query. The main

\subsection{FARMMANAGER: AN ANDROID APPLICATION FOR THE MANAGEMENT OF SMALL FARMS}

Theodoros Lantzos, George Koykoyris, Michail 
Tasks such as field definition, task operations, lists and reports and all farming use data can be submitted and carried on together in a smart phone at any farm working condition. the Farm Manager is an Android smart phone application and it creates the management base for recording and browsing of ground fields, field relations (occupied or rented land), cultivation and its tasks, equipment, employees and European cultivations reports and all of them to be performed by the touch of smart phone screen button. The use of software is currently freely available and there are more than one thousand farmers using it in Greece. The main drawback is it is applicable only for the small farms.

\subsection{AGROMOBILE: A CLOUD -BASED FRAMEWORK FOR AGRICULTURISTS ON MOBILE PLATFORM}

\author{
Shitala Prasad, Sateesh K. Peddoju and Debashis \\ Ghosh
}

They described the use of application for agricultural sectors. In this application, they have described the types of diseases and causes for the diseases and all the remedy steps for recovering from that disease. The main problem in this paper is the farmers are allowed to view only the disease details and remedy. They cannot view the other details which is required for the cultivation of crops. Also it is inefficient to use other applications for the other informations. So this application cannot satisfy all the requirements needed by the farmers.

\section{EXISTING WORK}

In existing system, the agricultural researchers may not be in the position to initiate or intimate based on their manual work. The major drawback in which it cannot be overcame is the data sets which is not efficient in the manual work. This is overcame by the researchers using the login implementation. Also in existing system SMS is used which is not that much efficient because farmer get the details which are unrelated to their request and also get only limited information which is not sufficient. Also sometimes messages are not received due to the bad network problems. If once the message is not received then it is not retransmitted which leads to loss of data.

\section{PROPOSED WORK}

In proposed system, we proposed to implemented for research students for identifying the particular seeds and in what time the farmers can plow the farm land and implement the process based on the seeds and fertilizers. All these information can be accessed by the android application which directs to the website on processing the request. We introduce four categories of login namely, (1) researchers (2) advise officer (3) farmers login and (4) fertilizers login. The researchers login involves the entry details of the seeds and farm land. The advise officer contains the details of the farm land strength. The farmers can view all the details which is included in each and every login. At last the fertilizers login include what kind of fertilizers can be used for the land and it is based on the statistics for previous years data sets and matched based on rainfall and it is displayed on the graphically. And an admin governs all the functions and verifies all the type of user and the entire system is secured such that no other user can modify the content. In this paper we use multitenant concept which shares the single piece of information to multiple users. The main advantage of this concept is no one can change the information unless authorized which in turn enhances the security in the system. Also gps is used which automatically detects the location and updates the database with the information. Admin also verifies the user by cross checking. The cloud is used to store large amount of information which can serve many farmers.

\section{ARCHITECTURE DIAGRAM}

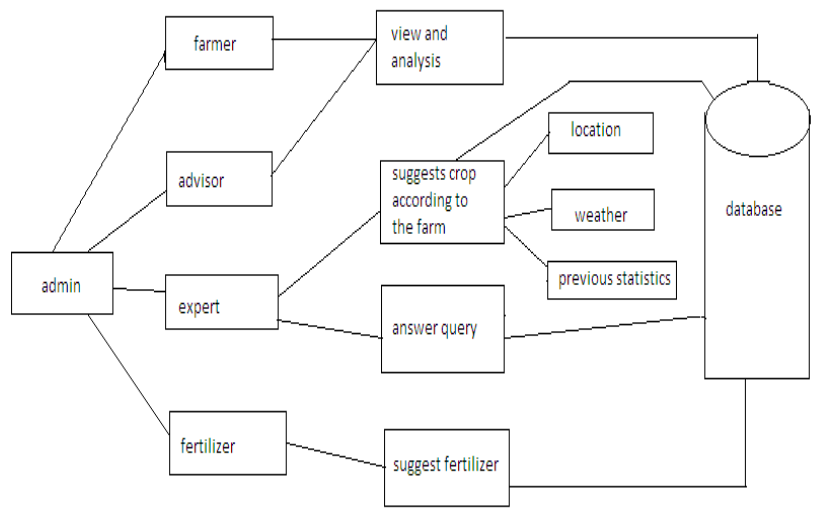

Fig. 5.1 Architecture diagram of full system.

\section{MODULE DESCRIPTION}

\subsection{FARMER DETAILS:}

The agricultural division officer will advises the farmer regarding farm land strength and if they plow the farm they get benefited or not. There are differentiated based on four categories namely, (1) researchers (2) advise officer (3) farmers login and (4) fertilizers login. Now a days farmer are upload their detail in the cloud based approach.To know about the details of agriculture.If any one search about the fertilize the seed to show the farmer details.Agriculture student can also search the farmer detail for suggestion to fertilize the seeds.

\subsection{RESEARCH EXPERT DETAILS}

The agriculture students are newly use the Agriculture field they don't know means ask the research experts.Research Expect means they are know about fertilize the seed and at last the fertilizers login include what kind of fertilizers can be used for the land and it is based on the statistics for previous years data sets and matched based on rainfall and it is displayed on the 
graphically. Rainfall details and when the seed is grown its is successfully growned or not fertilization limitations and water limitation every thing experts farmer knows the use it. agriculture details.

\subsection{WEATHER CALCULATION}

In this module, we calculate the weather details because the agriculture need a weather for $50 \%$ rainfall or summer all vitamin are need to grown a seeds now a days we are check the weather after we proceed a seed to fertilize and Expert can suggested to the weather condition is good after we fertilize the seed it will be grown better.

\subsection{GPS BASED SUGGESTION}

In this module, we identify the locations, where they are login to ask queries and the agriculture students and some farmer are don't know the locations where to seeds are fertile to grown the seed are better. GPS is now a days very useful for identify the locations and we can improve to fertile the seed in correct location.

\subsection{AGRICULTURE RELATED QUERIES}

If any query about the related agriculture to register to ask the expert suggestions.The advise officer contains the details of the farm land strength. The farmers can view all the details which is included in each and every login. At last the fertililzers login include what kind of fertilizers can be used for the land and it is based on the statistics for previous years data sets and matched based on rainfall and it is displayed on the graphically.

\subsection{MULTI TENANT BASED CLOUD APPROACH}

In this approach, we reduce the large set of data. In previous year agricultural details are stored that time the data set is huge and also time delay so we using the Multi tenant based cloud approach to implemented for research students for identifying the particular seeds and in what time the farmers can plow the farm land and implement the process based on the seeds and fertilizers. Farmers can view all the details based on land, seed and fertilizers etc. Large storage space for storing purpose. Manual record is maintained which may occur not a losss of data.Farmers can be view all the related details.

\section{CONCLUSION}

Diverse applications are produced and utilized by agriculturists for their particular reason. This applications have diverse utilization according to its functionalities. Numerous applications are being used for various sort of usefulness with respect to the cultivating exercises like trimming data, pesticides, manure, seed, offering of harvest, water system data,estimation of yield generation, climate data also, data in regards to the accepted procedures of cultivating. We found that a hefty portion of the applications are static. Rather than that element applications will be ideal to utilize. Likewise if all such recorded functionalities are package into the one single application and in the local dialect of the rancher, then it is anything but difficult to

\section{ACKNOWLEDGEMENT}

We exceptionally obliged to our guide for their direction and steady supervision and additionally to provide vital data in regards to the venture and likewise for their support in finishing the venture and our thanks and additionally go to my partner in building up the venture and individuals who have enthusiastically bailed me out with their capacities.

\section{REFERENCES}

[1] Steinberger, G., Rothmund, M., \& Auernhammer, H. (2009) -Mobile farm equipment as a datasource in an agricultural service architecturell, Computers and Electronics in Agriculture, 65(2), 238246.

[2] Lantzos, T., Koykoyris, G., \& Salampasis, M. (2013) -FarmManager: an Android application for themanagement of small farms $\|$, Procedia Technology, 8, 587-592.

[3] Voulodimos, A. S., Patrikakis, C. Z., Sideridis, A. B., Ntafis, V. A., \& Xylouri, E. M. (2010) - Acomplete farm management system based on animal identification using RFID technologyll,Computers and Electronics in Agriculture, 70(2), 380-388.

[4] Prasad, S., Peddoju, S. K., \& Ghosh, D. (2013) -AgroMobile: A Cloud-Based Framework forAgriculturists on Mobile Platforml, International Journal of Advanced Science and Technology, 59,4152.

[5] Singhal, M., Verma, K., \& Shukla, A. (2011, December) -Krishi Ville-Android based solution forIndian agriculturell, In Advanced Networks and Telecommunication Systems (ANTS), 2011 IEEE 5thInternational Conference on (pp. 1-5). IEEE.

[6] ICTinIndianAgriculture-DisseminatingInformationtoFarmers, http://www.iupindia.in/205/EE_ICT_in_Indian_Agriculture_44.html [7] KISSAN KERALA,

http://www.kissankerala.net/mobile/index.jsp\#mobile International Journal of Information Sciences and Techniques (IJIST) Vol.6, No.1/2, March 2016 